\title{
EPIDEMIOLOGICAL STUDY ON DIABETES PATIENTS ALONG WITH PATIENT INTERACTION AND COUNSELING
}

\author{
VIVEKANANDAN K ${ }^{1}$, BHAVYA E ${ }^{2 *}$, HARIKRISHNAN N ${ }^{1}$ \\ ${ }^{1}$ Department of Pharmacy Practice, Faculty of Pharmacy, Dr. M.G.R. Educational and Research Institute, Deemed to be University, Chennai, \\ Tamil Nadu, India. ${ }^{2}$ Department of Pharmacy Practice, School of Pharmaceutical Sciences, Vels Institute of Science, Technology and \\ Advanced Studies, Chennai, Tamil Nadu, India. Email: bhavyaekambaram@yahoo.com
}

Received: 06 December 2019, Revised and Accepted: 22 January 2020

ABSTRACT

Objective: The main objective was to study the prevalence of diabetes and to create the awareness of the diseases among the peoples who visited and admitted in tertiary care hospital at Chennai.

Methods: This study was carried out at Sir Ivan Stedford Hospital in Chennai. The data were collected from the outpatient department of diabetology. In our study, 150 diabetes mellitus (DM) patients were selected, which include visited or admitted in the hospitals. The pilot study used to observe DM patient for 3 months and the outcome was recorded. As per the standard guidelines, patient data collection form was prepared and got approval from diabetologist for collected patient data and pharmaceutical care issues.

Results: A total of 150 cases were collected for this study. The epidemiological evaluation study has expresses that female patients were more when compared to male patients. The survey results indicate that 62 numbers are literate people and 88 of them are illiterate. As per the survey, the results indicate that the diet followers are 92 and non-followers are 58. The findings show that in patients doing exercise are more when compared to non-exerciser. The alcohol consumers show 42 of DM patients. The survey results show that 42 peoples are alcohol consumers and 46 peoples are smokers.

Conclusion: The survey on epidemiological study on diabetes patients demonstrated the prevalence of DM and the patient's adherence to diabetic care. In our study, we guided patients based on their diet and exercise through counseling. As a pharmacist, we render our services to patients.

Keywords: Diabetes mellitus, Epidemiology, Pharmaceutical services, Counseling.

(C) 2020 The Authors. Published by Innovare Academic Sciences Pvt Ltd. This is an open access article under the CC BY license (http://creativecommons. org/licenses/by/4. 0/) DOI: http://dx.doi.org/10.22159/ajpcr.2020.v13i3.36555

\section{INTRODUCTION}

The prevalence of diabetes is rapidly rising all over the globe at an alarming rate. Over the past 30 years, the status of diabetes mellitus (DM) has changed from being considered as a mild disorder of the elderly to one of the major causes of morbidity and mortality affecting the youth and middle-aged people [1]. It is significant to note that the rise in prevalence is seen in all six populated continents of the globe. Although there is an increase in the incidence of Type 1 diabetes also, the major driver of the epidemic is the 2017 more common form of diabetes, namely, Type 2 diabetes, which interprets for more than $90 \%$ of all diabetes cases [2]. Nowhere is the diabetes epidemic more pronounced than in India as the World Health Organization reports show that 32 million people had diabetes in the year 2002 [3-5]. The International Diabetes Federation estimates the total number of diabetic subjects to be around 40.9 million in India and this is advance set to rise to 69.9 million by the year 2025 [6].

\section{METHODS}

\section{Subjects and settings}

This study was carried out at Sir Ivan Stedford Hospital in Chennai. The data were collected from the outpatient department of diabetology.

\section{Sample size}

In our study, $150 \mathrm{DM}$ patients were selected, which include visited or admitted in the hospitals.

\section{Study design}

The pilot study used to observe DM patient for 3 months and outcome was recorded [7-9].

\section{Study criteria}

Inclusion

The following criteria were included in the study:

1. Patient above 18 years and below 80 years

2. Patient with DM and with symptoms

3. Data to be collected outpatient of DM

4. Patient able to read and write the consent form.

\section{Exclusion}

The following criteria were excluded from the study:

1. Patient below 18 years

2. Patients are not visited diabetology department

3. Other disease and disorder data not collected

4. Patients who were unable to read and write the consent form.

Study material

Patient data collection form

As per the standard guidelines, patient data collection form was prepared and got approval from diabetologist for collecting patient data and pharmaceutical care issues. The form contains demographic data such as age, social history, family history, current treatment regimen, and change of prescription drugs [10].

\section{RESULTS AND DISCUSSION}

The epidemiological evaluation study has expresses that Fig. 1 indicates female patients (90) more comparatively male patients (60). The DM patients are more in old age groups (54\%) who were available in the tertiary hospital when compared to each other age group of patients, 


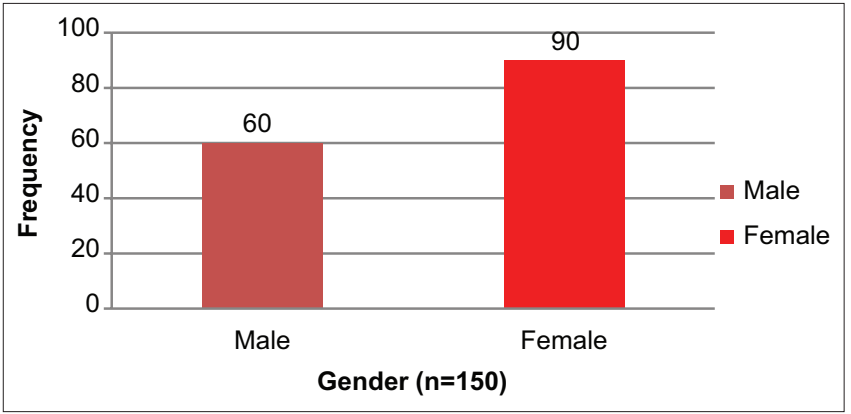

Fig. 1: Gender

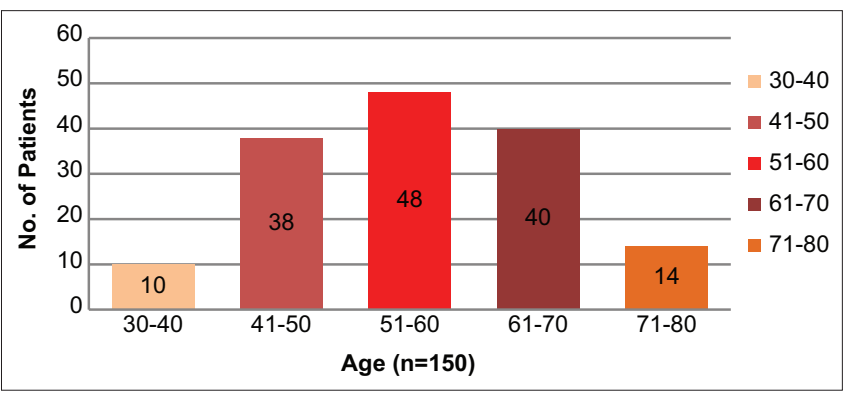

Fig. 2: Age

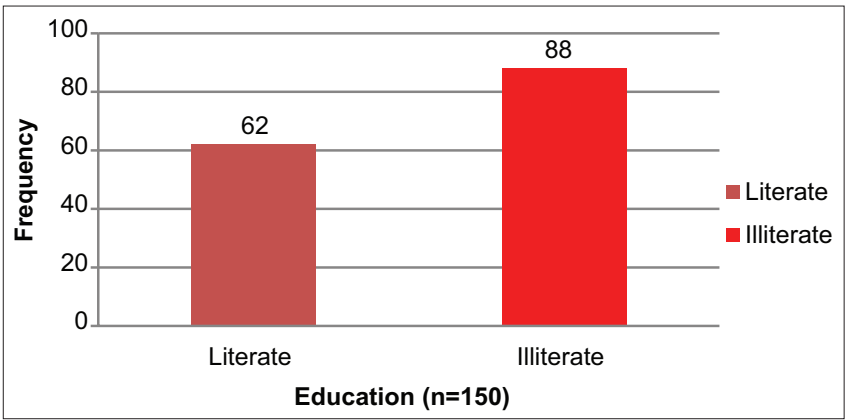

Fig. 3: Education

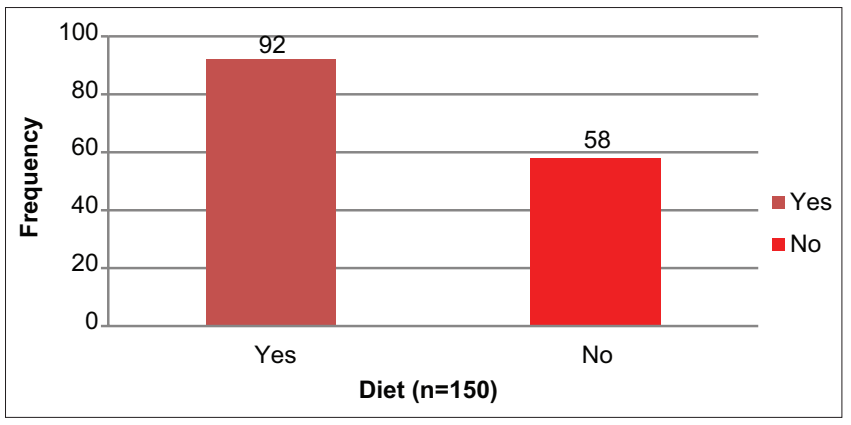

Fig. 4: Diet and non-diet followers

as shown in Fig. 2. The survey results are indicated in Fig. 3, the literate people (62) and illiterate people (88). As per the survey, Fig. 4 indicates that the diet followers are 92 no's and non-followers are 58 no's. The findings are shown in Fig. 5; patients doing regular exercise were 87 patients and non-exerciser were 63 patients. Fig. 6 indicates that the alcohol consumers are 42 patients. The survey results show that 46 patients are smokers who were affected in DM, as shown in Fig. 7.

\section{CONCLUSION}

The present study was conducted on subjects with DM to evaluate the risk factors related to the complications of the disease who were visited

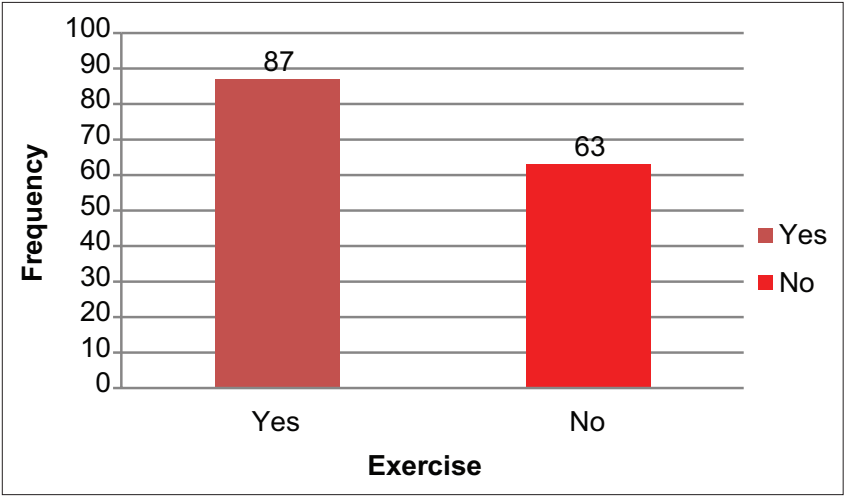

Fig. 5: Exercise

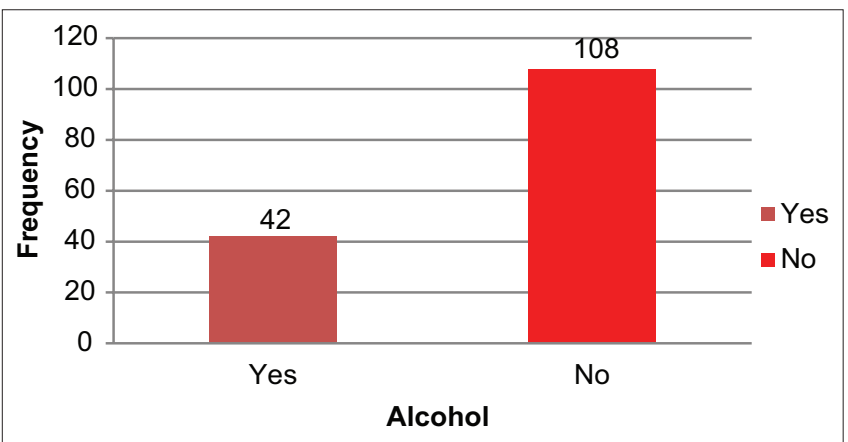

Fig. 6: Consumption of alcohol

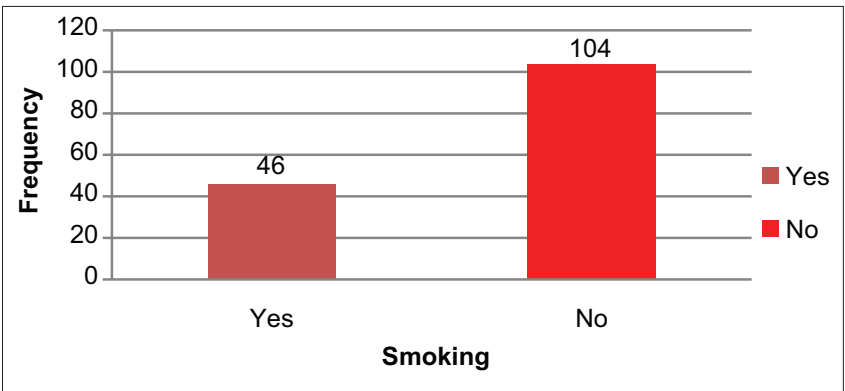

Fig. 7: Smoking habit

the tertiary care hospital. The periodical intensive counseling on diet and exercise has helped in managing the body weight and body mass index (BMI) of these patients. Reduction in body weight and BMI will help in the overall control of the condition. As a pharmacist, we render our services to patients.

\section{AUTHORS' CONTRIBUTIONS}

All the authors were actively involved in conducting the survey.

\section{CONFLICTS OF INTEREST}

We declare that there are no conflicts of interest.

\section{AUTHORS' FUNDING}

All the authors are funded equally. Not funded by agents.

\section{REFERENCES}

1. International Diabetes Federation. IDF Atlas of Diabetes. $5^{\text {th }}$ ed. Belgium: International Diabetes Federation; 2011.

2. Harris M, Zimmet P. Classification of diabetes mellitus and other categories of glucose intolerance. In: Alberti K, Zimmet P, Defronzo R, editors. International Textbook of Diabetes Mellitus. $2^{\text {nd }}$ ed. Chichester: 
John Wiley and Sons Ltd.; 1997. p. 9-23,33.

3. World Health Organization. Prevention of Diabetes Mellitus, Report of a WHO Study Group. Geneva: World Health Organization; 1994.

4. Malaisse W. Metabolic signalling of insulin secretion. Diabetes Rev 1996;4:145-59.

5. Piero MN, Nzaro GM, Njagi JM. Diabetes mellitus-a devastating metabolic disorder. Asian J Biomed Pharm Sci 2014;4:1-7.

6. Mahler RJ, Adler ML. Type 2 diabetes mellitus: Update on diagnosis, pathophysiology, and treatment. J Clin Endocrinol Metab 1999;84:1165-71.

7. Sulthan N. Perception of clinical research among clinical investigators in Saudi Arabia. Asian J Pharm Clin Res 2015;8:243-6.

8. Keban SA, Abdillah S, Najuah N. The role of pharmacists in evaluating and intervening the patients with diabetic neuropathy. Asian J Pharm Clin Res 2017;10:127-31.

9. Baby A, Varghese AA, Jose C, Kandasamy K, Rajagopal SS. A prospective evaluation of causes and treatment of infertility in a tertiary care hospital, Erode. Asian J Pharm Clin Res 2018;11:149-53.

10. Vivekanandan K, Bhavya E, Punitha K, Anand NV. A study on poison cases and their management along with poison awareness educational strategies. Asian J Pharm Clin Res 2015;5:1-5. 